\title{
RELAPSING POLYCHONDRITIS. A CASE REPORT AND BRIEF INTRODUCTION TO THE DISEASE
}

\author{
Filka Georgieva, Sonya Marina \\ Department of Infectious Diseases, Parasitology and Dermatovenereology, \\ Faculty of Medicine, Medical University of Varna
}

\begin{abstract}
Relapsing polychondritis (RP) is a rare immune-mediated disease that occurs with recurrent inflammatory processes in cartilage structures and tissues rich in proteoglycans throughout the body, in particular the ears, nose, eyes, and joints. The long time between relapses makes diagnosis difficult and often the disease remains unrecognized. We present a case of a 56-year-old patient diagnosed with RP. The diagnosis is based on clinical indicators: polyarthritis, chondritis on ear cartilage, and good response to corticosteroid treatment.
\end{abstract}

Keywords: relapsing polychondritis, rare disease, erysipelas-like inflammation

\section{INTRODUCTION}

Relapsing polychondritis (RP) is a rare immune-mediated condition that occurs with recurrent inflammatory processes in cartilage structures and tissues rich in proteoglycans throughout the body, in particular the ears, nose, eyes, joints and airways (Orpha code: 728). The process leads to anatomical deformations and disturbances in the normal functioning of the affected structures. The unclear etiology and pathogenesis, as well as the fact that the disease is extremely rare, complicate both diagnosis and therapy.

\footnotetext{
Address for correspondence:

Filka Georgieva

Faculty of Medicine

Medical University of Varna

55 Marin Drinov St

9002 Varna

e-mail:filka@abv.bg
}

Received: October 16, 2019

Accepted: December 8, 2019

\section{PRESENTATION}

We present a 56-year-old female patient who was hospitalized for erysipelas-like inflammation of both ears in 2019. On admission, the patient complained of nighttime shortness of breath and feeling of oppression in the larynx area. She also reported hearing problems and headache. From her medical history: in 2012, the left knee joint was replaced, and in 2018, the right hip joint was replaced. The dermatological status showed well-defined edema and erythema bilaterally in the area of the ear cartilage. Desquamation and palpation tenderness were observed. From the performed research, laryngoscopy was established as normal. The Ro graph of the lung was normal. No deviation was observed in the blood count incl. RF, except for ESR and CRP, which were slightly elevated. Biopsy of the right auricle revealed a chaotic arrangement and fragmentation of collagen fibers, and loosening of the stroma. The antibiotic treatment was without response. The improvement of symptoms started after corticosteroid treatment, which started with an initial dose of $50 \mathrm{mg} /$ day, fol- 
lowed by reduction by $10 \mathrm{mg}$ weekly until achieving a dose of 4-8 mg/day.

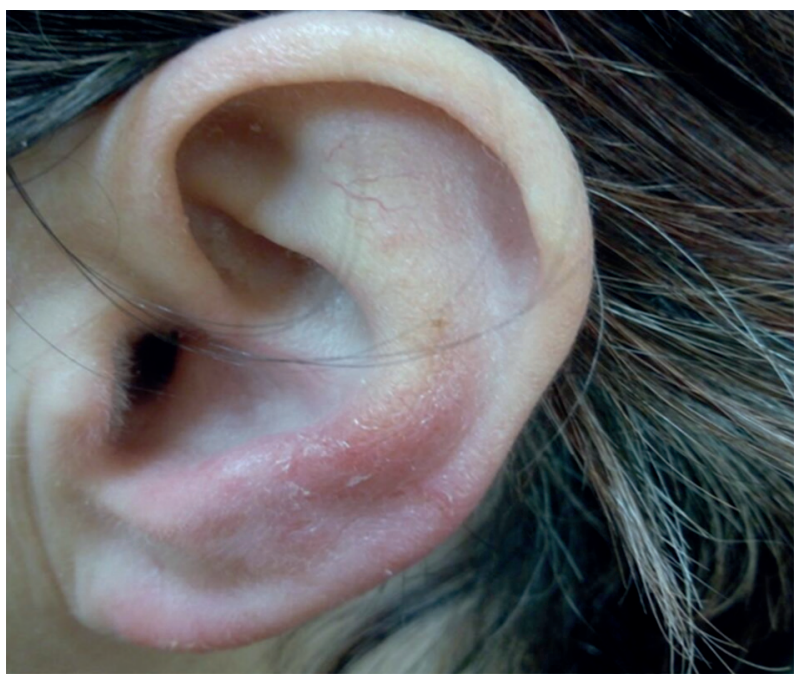

Fig. 1. Image of the left ear of the patient

\section{DISCUSSION}

$\mathrm{RP}$ is a multisystem autoimmune disease with a diverse clinical picture and without clear diagnostic and therapeutic criteria. Its relatively late recognition is a major cause of complications and deformities of the affected cartilage structures

In 1923, Rudolf Jaksch von Waetenhorst first described the disease and named it polychondropathia (1). Later, patients with similar symptoms were described by other authors under different names until 1960, when Pearson and coauthors introduced the current name emphasizing the recurrent nature of the disease (2).

Annual incidence varies from 0.71 to 3.5 per million according to different authors (3). Most often, the first manifestation is between 40 and 60 years of age, although RP may also occur in childhood. Pediatric RP cases represent up to $5 \%$ of all patients. The age range is between 1.7 months and 17 years (4). Pregnancy is not affected by the disease (5). No neonatal cases have been described. Epidemiological researches reveal a slight prevalence of female patients.

The etiology is unknown. A link between RP and HLA class II, in particular HLA-DR4, has been described (6). In the literature, cases of RP after drug or toxin incidents have been revealed (7).
Based on found deviations in autoantibodies against collagen II, IX, XI, matrilin-1 and COMP (cartilage oligomeric matrix complex) as well as considering the role of cell-mediated immunity (IL2, IL12, matrix metalloproteinase (MMP) -3, 8, 9 and cathepsins K, L), the most likely hypothesis for the pathogenesis of the disease is that unknown factors (infection, mechanical or chemical aggressor) provoke protein degranulation and lead to release of specific antigens against cartilage structures (8-10).

The clinical presentation is dominated by chondrites of the auricle - 90\% (11), nasal cartilage 54\% (12), and laryngotracheobronchial - 10\% (13) involvement. The second most common symptom of the disease is arthropathy (11). Eye changes, nervous system symptoms, renal changes, and various skin conditions and lesions are relatively common $(14,15)$.

There have been a number of reports of the association of RP with other diseases. The most often mentioned are: autoimmune diseases, rheumatologic diseases, vasculitis, myelodysplastic syndrome, tumors (bladder, breast, lung, and pancreas), and lymphomas (16).

The diagnosis is challenging due to the lack of specific clinical, histological and laboratory findings (17). The first diagnostic criteria were offered by McAdam on the basis of the observation of 159 patients. Later, Damiani and Leveni, as well as Michet and associates, modified these criteria (18).

The unclear etiology and pathogenesis, as well as the fact that the disease is extremely rare, complicate not just the diagnosis but the therapy as well. There are single and unsystematic reports in the literature on the use of various drugs with variable effect. Studies on the benefits of corticosteroid treatment are still numerous, but these drugs do not prevent recurrences and subsequent complications of RP. Therapy also could be performed with dapsone or colchicine. Individual patients show good response when administered biologics. The biologic agents used to treat RP include tumor necrosis factor inhibitors, rituximab, anakinra, tocilizumab, abatacept, and others.

The Relapsing Polychondritis Disease Activity Index (RPDAI) is relatively new score, which is designed to evaluate disease activity in a standardized manner. It consists of 27 individual assessment ques- 
tions, each ranging from 1 to 24 . Theoretically, the maximum RPDAI is 265 , reporting over a period of 28 days (19).

\section{CONCLUSION}

The presented case of a patient with a rare disease (RP) is interesting for practitioners who are unfamiliar with this pathology, and, as a rule, making a diagnosis presents significant difficulties. The lack of clinical criteria, specific histological and blood count changes, as well as the long time interval between relapses, complicates the diagnosis and is a prerequisite for deformities in the area of the affected cartilage. In our case, it took 7 years from the first episode of the disease to the correct diagnosis.

\section{REFERENCES}

1. Jaksch-Wartenhorst R. Polychondropathia. Wien Arch Inn Med. 1923; 6:93-100.

2. Pearson CM, Kline HM, Newcomer VD. Relapsing polychondritis. N Engl J Med. 1960;263:51-8. doi: 10.1056/NEJM196007142630201.

3. Horváth A, Páll N, Molnár K, Kováts T, Surján G, Vicsek T, et al. A nationwide study of the epidemiology of relapsing polychondritis. Clin Epidemiol. 2016; 8:211-30.doi: 10.2147/CLEP.S91439.

4. Borgia F, Giuffrida R, Guarneri F, Cannavò SP. Relapsing polychondritis: An updated review. 2018. Biomedicines;6(3):84. doi: 10.3390/ biomedicines6030084.

5. Papo T, Wechsler B, Bletry O, Piette AM, Godeau P, Piette JC. Pregnancy in relapsing polychondritis: Twenty-five pregnancies in eleven patients. Arthritis Rheum. 1997;40(7):1245-9. doi: 10.1002/1529-0131(199707)40:7<1245::AIDART8>3.0.CO;2-\#.

6. Lang B, Rothenfusser A, Lanchbury JS, Rauh G, Breedveld FC, Urlacher A, et al. Susceptibility to relapsing polychondritis is associated with HLADR4. Arthritis Rheum. 1993; 36(5):660-4.doi: 10.1002/art.1780360513.

7. Berger R. Polychondritis resulting from intravenous substance abuse. Am J Med. 1988; 85(3):415-7. doi: 10.1016/0002-9343(88)90597-9.

8. Vitale A, Sota J, Rigante D. Lopalco G, Molinaro F, Messina $\mathrm{M}$, Iannone $\mathrm{F}$, et al. Relapsing polychondritis: an update on pathogenesis, clinical features, diagnostic tools, and therapeutic perspectives.
Curr Rheumatol Rep. 2016;18(1):3. doi: 10.1007/ s11926-015-0549-5.

9. Foidart JM, Abe S, Martin GR, Zizic TM, Barnett EV, Lawley TJ, et al. Antibodies to type II collagen in relapsing polychondritis. $\mathrm{N}$ Engl J Med. 1978; 299(22):1203-7.doi: 10.1056/ NEJM197811302992202.

10. Lahmer T, Treiber M, von Werder A, Foerger F, Knopf A, Heemann U, et al. Relapsing polychondritis: an autoimmune disease with many faces. Autoimmun Rev. 2010;9(8):540-6. doi: 10.1016/j. autrev.2010.02.016.

11. Buckner JH, Wu JJ, Reife RA, Terato K, Eyre DR. Autoreactivity against matrilin-1 in a patient with relapsing polychondritis. Arthritis Rheum. 2000; 43(4):939-43.doi: 10.1002/1529-0131(200004)43:4<939::AID-

ANR28 $>3.0 . C O ; 2-Z$. -

12. Longo L, Greco A, Rea A, Lo Vasco VR, De Virgilio A, De Vincentiis M. Relapsing polychondritis: a clinical update. Autoimmun Rev. 2016;15(6):53943.doi: 10.1016/j.autrev.2016.02.013.

13. Moon, SY, Lee JA, Joung MK, Chung DR, Song JH, Peck KR. Nasal deformity due to tuberculous chondritis. Clin Exp Otorhinolaryngol. 2014;7(3):22931.doi: 10.3342/ceo.2014.7.3.229.

14. Sharma A, Law AD, Bambery P, Sagar V, Wanchu A, Dhir V, et al. Relapsing polychondritis: clinical presentations, disease activity and outcomes. Orphanet J Rare Dis. 2014; 9:198. doi: 10.1186/ s13023-014-0198-1.

15. Michet CJ, Post TW, editors, Clinical manifestations of relapsing polychondritis. Waltham, MA: UpToDate; 2018.

16. Francès C, el Rassi R, Laporte JL, Rybojad M, Papo T, Piette JC. Dermatologic manifestations of relapsing polychondritis. A study of 200 cases at a single center. Medicine (Baltimore). 2001;80(3):173-9. doi: 10.1097/00005792-200105000-00003.

17. Ludvigsson JF, van Vollenhoven R. Prevalence and comorbidity of relapsing polychondritis. Clin Epidemiol. 2016;8:361-2.doi: 10.2147/CLEP.S121272.

18. Rednic $S$, Damian L, Talarico R, Scirè CA, Tobias A, Costedoat-Chalumeau N, et al.Relapsing polychondritis: state of the art on clinical practice guidelines. RMD Open. 2018;4(Suppl 1):e000788. doi: 10.1136/rmdopen-2018-000788.

19. www.RPDAI.org 